\title{
Behavioral Health Theories, Equity, and Disparities in Global Health:
}

\section{A Basic Process Model}

\author{
Lauren E. McKinley ${ }^{1}$, Kaylyn McAnally ${ }^{1}$, Susette Moyers ${ }^{1}$, \& Martin S. Hagger ${ }^{1,2}$ \\ ${ }^{1}$ Psychological Sciences, University of California, Merced \\ ${ }^{2}$ Faculty of Sport and Health Sciences, University of Jyväskylä
}

\begin{abstract}
Author note
Martin Hagger's contribution was supported by a Finnish Distinguished Professor (FiDiPro) award from Business Finland (1801/31/2015). The authors declare no interests relating to this manuscript.

Correspondence concerning this article should be addressed to Martin S. Hagger, SHARPP Lab, Psychological Sciences, University of California, Merced, 5200 North Lake Road, Merced, CA 95343, USA. Email: mhagger@ucmerced.edu
\end{abstract}

Full reference: McKinley, L. E., McAnally, K., Moyers, S., \& Hagger, M. S. (2020). Behavioral health theories, equity, and disparities in global health: A basic process model. In R. Haring, I. Kickbusch, D. Ganten \& M. R. Moeti (Eds.), Handbook of Global Health. New York, NY: Springer Nature. https://doi.org/10.1007/978-3-030-05325-3_58-1 


\section{B. Abstract}

Lack of participation in health promoting behaviors and participation in behaviors that contribute to health risks have been linked to health disparities observed among individuals from disadvantaged backgrounds. This chapter presents a basic process model to summarize the effects of socio-structural variables linked to health disparities - socio-economic status, education, health literacy, ethnicity, and religiosity - on individuals' beliefs and cognitions that determine behavior. Socio-structural characteristics were proposed to have a pervasive effect on individuals' beliefs and other constructs from social cognition theories which impact their decisions to participate in prospective health behaviors and influence their health outcomes. The model provides a mechanistic explanation for health disparities among individuals from disadvantaged groups. A series of illustrative examples are presented of the application of the proposed model as a means to explain how characteristics linked to disadvantage relate to participation in health behaviors and outcomes via potentially modifiable mediating beliefs and social cognition constructs. Efforts to develop interventions targeting these modifiable beliefs will contribute to the enhancement of long-term global health and illness prevention.

\section{Keywords}

Keywords: health disparities, beliefs, social cognition theories, health literacy, religiosity 


\section{Introduction}

\section{Behavior and Health}

Research in the health domain has established links between health-related behaviors and health outcomes. For example, studies have linked screening attendance, immunization, maintaining a healthy diet, participating in physical activity, and adherence to medication to adaptive health outcomes (Lee and Loke 2005; Hyde et al. 2012; Lippke et al. 2012; Mojtabai and Olfson 2003), and with decreased risk of chronic conditions and illnesses such as cardiovascular disease, obesity, cancer, and diabetes (Onat 2001; Li et al. 2019; Ouyang et al. 2012; Mesas et al. 2012). However, despite consistent evidence supporting the relations between participation in these behaviors and reduced chronic illness risk and long-term health benefits, rates of participation in these behaviors are typically low (Murimi and Harpel 2010).

For example, colorectal cancer is the third most common cancer worldwide (International Agency for Research on Cancer 2018). Screening by faecal occult blood testing has been shown to reduce the incidence of colon cancer through detection and removal of precancerous lesions, and also to significantly reduce mortality rates associated with the disease through early detection (Hewitson et al. 2007 2008). However, despite the potential benefits, screening uptake rates remain markedly low (Decker et al. 2015; Joseph et al. 2012). Similarly, although it has been established that maintaining a healthy diet and engaging in regular physical activity can contribute to minimizing obesity, prevalence rates of the condition are rising (Hales et al. 2018). This is particularly problematic because obesity is associated with an increased risk of many maladaptive health conditions and illnesses such as type 2 diabetes, hypertension, and heart disease (Kopelman 2007). Consumption of a diet with excess sugar and saturated fat has been shown to be a major contributing factor to obesity risk, and yet prevalence rates continue to rise. These examples illustrate that despite evidence indicating participation in health behaviors is 
linked to better health outcomes and reduced disease risk, participation in such behaviors remains low (Murimi and Harpel 2010).

\section{Health Disparities and Health Behavior}

Incidence of chronic disease is not evenly distributed across populations. Individuals from certain groups such as those from lower socio-economic backgrounds, underserved communities, and certain ethnic minority backgrounds have been shown to have elevated incidence of chronic conditions relative to those from middle and higher socio-economic backgrounds and communities, and from majority ethnic groups (Crook and Peters 2008; Freedman et al. 2011; LaVeist et al. 2000). In addition, these groups have been shown to have lower participation rates in preventive health behaviors such as eating a healthy diet, engaging in the recommended amount of physical activity, attending cancer screenings, receiving proper immunizations, and adhering to medication and treatment regimens (Pampel et al. 2010; Johnson et al. 2008; August and Sorkin 2011; Chu et al. 2004; Rolnick et al. 2013). Lack of participation in such preventive health behaviors can lead to systematic differences among individuals' health statuses. These systematic differences are often referred to as health disparities. Health disparities have been defined as differences in health status that negatively and systematically impact individuals belonging to disadvantaged groups (Braveman 2006). A myriad of sociostructural factors has been shown to be associated with group differences in health status including socioeconomic status (SES), level of education, gender, sexual orientation, disability status, race, ethnicity, and religious affiliation (Dehlendorf et al. 2010; Hartley 2004; Koenig et al. 2001). Health disparities are often conceptualized in terms of the differences which exist in the quality of health care that individuals receive, specifically regarding those that receive a 
lower quality of care that is unrelated to the degree of access they have to facilities, their preferences and needs, or the appropriateness of intervention (Nelson 2002). These kinds of differences in health status, and the reduced quality of care that those belonging to disadvantaged groups receive, have been linked to poorer health outcomes and engagement in negative health behaviors among a wide variety of illness populations (Nelson 2002; Myers et al. 2003).

Given the documented disparities in health among certain groups, governments, public health organizations, and healthcare providers have made gaining a better understanding of the relationships between health outcomes and health disparities a priority (Haider et al. 2016). One key issue is that health disparities may be represented by various structural differences manifested in groups with certain characteristics such as poor investment in healthcare programs, lack of access to healthcare and health insurance, and poor health literacy and education (Basu et al. 2012; Waverijn et al. 2016; DeWalt et al. 2004). Other influences may be differences in how individuals from particular social or ethnic groups may be treated including endemic prejudice and discrimination within the healthcare system (Sawyer et al. 2012). These structural and systematic differences have a direct impact on health outcomes by presenting barriers to good health care or preventing access altogether (Pascoe and Richman 2009; Chen et al. 2005). However, such factors may also affect health outcomes in disadvantaged groups indirectly through deleterious psychological effects. For example, disadvantaged groups may experience increased stress, anxiety, and negative affect from not being able to access healthcare or being denied access, or, more broadly, being disadvantaged or denied access to other services, which may have maladaptive effects on their mental and physical health, independent of the conditions for which they are seeking help (Watson et al. 2008; Sawyer et al. 2012). 


\section{Health Disparities and Determinants of Health Behavior}

The effect of disadvantage within the healthcare system on individuals' beliefs about prevention, healthcare, and health behaviors may be implicated in health disparities (Wardle et al. 2016; Schüz et al. 2017; Schüz et al. 2020). Experiences of disadvantage, prejudice, and unfavorable treatment may, over time, engender future expectations of disadvantage and discrimination. Such expectations may lead to negative beliefs about healthcare provision, and subsequently affect individuals' perceptions of the efficacy of health care and their perceived control over their health regardless of whether or not the socio-structural factors that led to the perceived disadvantage remain (Sawyer et al. 2012). These experiences may also affect beliefs and attitudes toward participating in preventive health behaviors or seeking care in the future (Orbell et al. 2017). Such beliefs may also be engendered by implication through the overall experience of disadvantage and prejudice present in many community systems and services more broadly, which can reduce individuals' overall beliefs in the efficacy of services rendered in specific contexts such as healthcare, in which disadvantage and discrimination may have not been experienced directly (Orbell et al. 2017). Taken together, the reason for the substantive health disparities in terms of adherence to health service use and participation in health behaviors among individuals from disadvantaged backgrounds is due to low beliefs in the efficacy of healthcare systems and the effectiveness of treatment when it is sought out (Orbell et al. 2017; Beauchamp et al. 2015).

In addition to effects of experience of disadvantage on beliefs about the efficacy of healthcare and prevention, other variables that indicate disadvantage may also influence individuals' beliefs toward participating in preventive behaviors. For example, low health literacy and education on preventive health may also cause individuals to believe that 
participating in preventive health behaviors will not be beneficial (Hagger et al. 2018; Hawkins 2011; Liu et al. 2015). These beliefs can then reduce individuals' self-efficacy - confidence in one's ability to deal with prospective situations - and desire to participate in behaviors associated with prevention of illness and promotion of health (Adams et al. 2013). In addition, individuals with low education and health literacy may also lack confidence in their healthcare providers or in the healthcare system in general because they experience difficulty understanding medical terminology and the implications of increasing participation in health promoting behaviors and decreasing engagement in health compromising ones (Beauchamp et al. 2015; Sentell et al. 2014). Thus, low health literacy and education may cause individuals to feel insecure about their own ability to partake in preventive and promoting health behaviors, and to also doubt the effectiveness of engaging in those behaviors. As a result, it is possible that health disparities observed among those from disadvantaged backgrounds with low health literacy and education may be, in part, due to their attitudes and beliefs about health behaviors.

A further important socio-structural factor that has been shown to be related to health outcomes is religiosity. Research has indicated that religiosity is associated with participation in health behaviors and health outcomes (Williams and Sternthal 2007; Miller and Thoresen 2003; Koenig et al. 2001). These effects can be attributed to the beliefs endorsed by individuals who identify with a particular faith. Common to many faiths is the belief that health is not under personal control and is, instead, determined by a deity or god. Such beliefs have been shown to be related to lower participation in health behaviors for illness prevention (e.g., screening for disease, immunization) seeking health care (e.g., scheduling medical appointments), and taking up or maintaining treatment regimens (e.g., medication adherence; Shelton et al. 2013; Benjamins and Brown 2004; Benjamins et al. 2006). Links between religious beliefs and health 
behaviors are not always clear cut or universal, however, and individuals from some faiths view health maintenance as a duty or obligation to their deity. These individuals have been shown to be more likely to engage in health promoting behaviors compared to those not holding such beliefs (Mahoney, Pargament et al. 2005). Research on religiosity in health contexts has tended to focus on how religious beliefs affect individuals' views regarding the efficacy of the healthcare system and their willingness to seek medical treatment (Morton et al. 2017; Pargament et al. 2005; Park 2007). This emerging research suggests that religious beliefs may be an important correlate of health beliefs and may be implicated in the processes by which those beliefs relate to actual participation in health behaviors.

\section{A Process Model Linking Socio-Structural Variables with Health Behaviors}

Although links between health inequalities and many health behaviors have been well established (Harrell et al. 1998; Liu et al. 1982; Winkleby et al.1990), there remains a paucity of research directly examining the effects of socio-structural variables related to health disparities on health behaviors and outcomes. Effects of socio-demographic and structural variables linked to health disparities such as SES, education, health literacy, ethnicity, and religiosity on health behaviors and health outcomes can be summarized in a basic process model. The model outlines the processes by which these variables affect health behaviors and outcomes. Specifically, the model proposes that effects of these socio-structural variables impact individuals' participation in health behaviors through the mediation of the immediate determinants of those behaviors derived from social cognition theories of behavior. Furthermore, whether or not an individual avoids, or takes up and adheres to, health promoting behaviors can determine long-term health outcomes, such as chronic disease risk. The basis of the model is that social-structural variables serve as a source of information for the belief-based constructs from social cognition theories 
that serve as the immediate determinants of behavior. Individuals' social context and environment, therefore, is proposed to have a pervasive effect on their beliefs which ultimately determines their decisions to participate in health behaviors. Such differences are proposed to be implicated in the processes by which socio-structural variables relate to health behaviors and health outcomes, and, therefore, provide an explanation, at least in part, for the disparities observed among the health outcomes of individuals belonging to disadvantaged groups.

The proposed model is presented in Figure 1. In the model, socio-structural variables (e.g., SES, health literacy, religiosity) are indicated as predictors of social cognition beliefs (e.g., attitudes, beliefs, self-efficacy, etc.), represented by path $a$ in Figure 1. The beliefs are proposed as determinants of health behaviors, illustrated by path $b$ in Figure 1. The model, therefore, proposes indirect effects of socio-structural variables on health behavior and health outcomes mediated by social cognition beliefs relating to participation in health behaviors, represented by path $c^{\prime}$ in Figure 1. To the extent that beliefs fully account for the effect of socio-structural variables on health behavior, then the indirect (mediated) pathway comprising paths $a$ and $b$ should more or less fully account for the direct effect of socio-structural variables on health behavior (path $c^{\prime}$ ). It is important to note that the residual effect of an independent variable (such as a socio-structural variable in the present process model) on a dependent variable (such as participation in a health behavior in the process model) after a mediated effect has been accounted for (such as the effect that occurs through a mediator like a social cognition variable in the process model) is referred to as $c^{\prime}$ by convention. Analogously, the direct effect of the independent variable on the dependent variable is designated $c$ by convention. The difference in the two should equate to the mediated effect: $c-c^{\prime}=a \times b$. For further details, the reader is directed to Hayes' (2018) lucid treatment of the subject. Finally, health behaviors are proposed 
as the pre-cursors of health outcomes, which could be adaptive (i.e., reduced risk from chronic illness) in cases where individuals participate in health promoting behaviors, or maladaptive, in the case of health compromising behaviors (i.e., increased chronic disease risk). This effect is represented by path $d$ in Figure 1 .

The importance of the process model is that it can identify potentially modifiable targets for behavioral interventions that may promote increased participation in health behaviors. Many of the socio-structural variables related to health disparities are fixed and relatively unchangeable (e.g., ethnicity), or difficult to change (e.g., SES, education, health literacy). It may be more feasible and viable to target and change the beliefs and social cognition constructs that relate to engagement in health promoting behaviors through behavioral interventions. As a result, researchers in the field of behavior change have focused on identifying the psychological determinants of health as they provide the basis for the development of behavior change interventions (Hagger, Cameron et al. 2020; Hagger, Moyers et al. 2020; Rothman et al. 2020). This is because beliefs and social cognitive constructs are assumed to be readily modifiable through specific strategies and techniques that form the content of behavioral interventions. Recently, the National Institutes of Health (NIH) issued the Science of Behavior Change initiative which called for researchers to identify the mechanisms of behavior change, specifically the techniques that will reliably lead to behavior change through changing theorybased modifiable behavioural determinants (Aklin et al. 2020; Nielsen et al. 2018). The current model builds on this work by demonstrating how beliefs concerning health behaviors are implicated in observed health disparities. The model, therefore, provides an explanation for health disparities, and a set of hypotheses that can be tested empirically to provide the necessary evidence to support the proposed process. In addition, the model provides a template for 
behavioral interventions that may lead to improved health behavior among those affected by disadvantage by virtue of the social-structural variables.

The social cognition constructs referred to in the current process model as mediators of the relationship between socio-demographic variables and health behavior are derived from multiple extant theories. Theories such as the health belief model (Janz and Becker 1984), protection motivation theory (Rogers and Prentice-Dunn 1997), and the theories of reasoned action and planned behavior (Ajzen and Fishbein 1980; Ajzen 1985) suggest that behavior is a function of beliefs about the value or outcome of the behavior itself (e.g., attitudes, outcome expectancies), beliefs in the risk (e.g., perceived susceptibility, perceived vulnerability), perceived barriers or perceptions of control (e.g., perceived behavioral control, self-efficacy), and perceived social influences (e.g., normative beliefs, social support; for a summary see Fishbein et al. 2001; Hagger and Hamilton 2020; McMillan and Conner 2007; Protogerou, Johnson, and Hagger 2018). These constructs have been consistently related to participation in health behaviors for multiple behaviors and across multiple populations and contexts. Such research identifies potentially modifiable constructs that can be targeted in behavioral interventions. Theory on the mechanisms of behavioral interventions suggest that the content of behavioral interventions should affect behavior through the theory-based determinants (Hagger, Moyers et al. 2020; Rothman et al. 2020). Based on these models, a recent development of theory- and expert-verified links between the techniques that comprise behavioral interventions and the theory-based determinants has emerged (Carey et al. 2019; Connell et al. 2019). This provides essential information for health practitioners interested in selecting techniques to be used in behavior change interventions. Importantly, these advances in theory-based interventions have important ramifications for the current process model. If research guided by the process 
model can identify the social cognitive mediators of certain socio-structural variables on health behavior, those mediators become candidate targets for change in behavioral interventions. Knowledge of the techniques known to change those targets, therefore, provide essential information for those wishing to design interventions that will change behavior among groups whose health behavior may be compromised by socio-structural variables.

An illustrative example may provide insight on how the process model links with research on behavior change techniques, putative mediators of intervention effects from social cognition theories, and, ultimately, effective behavior change interventions that may serve to obviate the disparities attributable to effects of socio-structural variables. Orbell et al. (2017) examined the process by which ethnicity related to uptake of colorectal cancer screening tests in a process model. Previous research suggested that uptake of screening for colorectal cancer risk as part of a UK national screening program was associated with ethnicity; people from South Asian ethnic groups (Hindu-Gujarati/Hindi, Muslim-Urdu and Sikh-Punjabi) tended to have lower uptake rates than non-Asians. Based on the large-sample prospective data, they found that these groups were 1.6 times less likely to participate in colorectal screening. A process model, similar to that which was presented in Figure 1, revealed that effects of ethnicity representing the three South Asian groups were fully mediated by lower self-efficacy and higher perceived psychological costs of the procedure. In addition, ethnicity effects on beliefs were also mediated by socio-economic status. The researchers speculated that these effects reflected the higher perceived demand that an abnormal result would bring such as seeking treatment and taking time off from work - a matter of high importance given the likelihood of family dependency on their income and also the perceived difficulties they may encounter in dealing with the healthcare system (e.g., language barriers, perceived prejudice). Their lower confidence in their ability to 
take the test may reflect heightened disgust and embarrassment in the self-sampling screening procedure, particularly in group living conditions which may offer limited privacy. Taken together, these data provide support from the predictions of the basic process model outlined in Figure 1 and outline an important role that psychological beliefs may play in determining the effects of socio-structural variables like ethnicity and socio-economic status on health behaviors.

In summary, when considering health disparities and deleterious health outcomes, the process model suggests that psychological constructs fully or partially account for the link between socio-structural constructs indicative of disadvantage, participation in health-related behaviors, and compromised health status. The value of identifying such psychological mediators is that they provide insight into how interventions can be designed to specifically target and promote change in the relevant mediating beliefs and social cognition constructs associated with health behavior participation. Examples of how this model can be generalized to explain the relationships among the socio-structural factors associated with health disparities, health behaviors, and health outcomes, across a variety of different contexts, as mediated by psychological processes, will be discussed in the next sections accompanied by specific examples of these effects based on the proposed basic process model.

\section{E. Main Text}

\section{Socio-Demographic Variables}

Socio-demographic variables describe aspects and features of groups within populations and include age, gender, ethnicity, education level, and income. They are also used to differentiate groups within populations based on their absolute level or population-level ranking on one or more of these variables such as health status or SES (Jiang and Hesser 2006). Although some socio-demographic variables such as age, level of education, or income may vary over the 
course of a lifetime, others like ethnicity and racial group are not subject to change. The latter characteristics cannot, therefore, be designated as targets for change through intervention. Similarly, some socio-demographic characteristics can potentially be changed such as education level or income. However, change in these characteristics would require substantive change to multiple variables, many of them structural and out of the direct control of the individual. For example, changes in education level or income would likely require change in factors related to access, along with social and institutional support. In contrast, the current process model highlights the role of beliefs and social cognition constructs as mediators of the relationships between demographic characteristics and health behaviors and outcomes. These constructs are considered to be more easily changeable for individuals through behavioral interventions. Identifying these constructs and understanding how they can be altered through intervention is key for researchers who are designing interventions with the goal of decreasing health disparities and improving affected individuals' health outcomes.

Various socio-demographic characteristics such as ethnicity and minority status, low SES, and low level of education have been linked to maladaptive health outcomes such as increased risk of cancer, cardiovascular disease, diabetes, and depression (Doubeni et al. 2012; Glover et al. 2004; Everson et al. 2002). Furthermore, certain socio-demographic variables, specifically low SES and low level of education, have been linked to a greater all-cause mortality (Peterson et al. 2011). The proposed basic process model can be applied in research studying relations between socio-demographic variables and health behaviors participation to provide evidence supporting the potential role for beliefs and social cognition constructs in explaining health disparities. 
The study conducted by Orbell et al. (2017) in the context of ethnicity and colorectal cancer screening provided in the previous section was an example that illustrated the role beliefs play in mediating effects of socio-demographic constructs on health behavior and health outcomes. A further illustrative example is provided in the systematic review conducted by Johnson et al. (2008) on cervical cancer screening behaviors among immigrants and ethnic minorities. They found that beliefs held by individuals belonging to these demographic groups influenced their health outcomes. Specifically, results indicated that there were commonly held beliefs among minority individuals that were related to their screening decisions such as fatalistic attitudes (e.g., negative expectations), lack of cervical cancer knowledge, fear, and misconceptions regarding susceptibility and need. As with Orbell et al.'s (2017) findings, these findings indicated that individuals from minority backgrounds are more likely to hold beliefs that reflect their social and environmental conditions, such as their access to resources and education level, as well as their experiences with the healthcare system. These beliefs lead them to be less likely to participate in health behaviors likely to bring about adaptive change in their health outcomes and risk from chronic conditions. Taken together, the findings of Orbell et al. (2017) and Johnson et al. (2008) illustrate how socio-demographic constructs are related to psychological cognitions and beliefs which, in turn, predict health behaviors and potential health outcomes, in this case screening participation and the potential to develop cancer. These effects are illustrated in the specific form of the generic process model (Figure 1), illustrated in Figure 2a.

Other beliefs, which may be implicated in effects of ethnicity and race on poorer health outcomes and health disparities, include beliefs with respect to racism and discrimination. Beliefs about discrimination have been consistently linked to health behaviors and outcomes 
(Pascoe and Richman 2009; Chen et al. 2005). For example, research has shown that race and ethnicity are associated with worse health outcomes mediated by individuals' perceived discrimination (Pascoe and Richman 2009). Perceived discrimination contributed to psychological and physiological stress responses, which resulted in engagement in unhealthy behaviors, and was, therefore, associated with worse physical and mental health outcomes. Another study indicated that perceived racism in the health care system was associated with preferences of physicians of the same race among ethnic minorities (Chen et al. 2005). These findings further indicate that perceived racism may impact health outcomes, especially regarding individuals' decisions to seek care if physicians were of a different race. These findings are represented in the specific version of the process model in Figure 2b. Taken together, they illustrate how socio-demographic variables are related to beliefs including perceived racism and discrimination, which then predict health behaviors, like physician selection and use of the health care system, which, in turn, affect health outcomes. The beliefs discussed above may also reduce individuals' overall beliefs in the efficacy of their healthcare providers or in the healthcare system as a whole. This may manifest in lower willingness to participate in health behaviors and maladaptive outcomes and increased health disparity.

\section{Health Literacy}

Health literacy is another socio-demographic factor shown to be related to health disparities. Health literacy is defined as the degree to which individuals have the capacity to obtain, process, and understand basic health information and services needed to make appropriate health decisions (Baker et al. 2006). It is typically assessed using validated questionnaires which have demonstrated good sensitivity and specificity in detecting inadequate health literacy in populations (Chew et al. 2008). Health literacy is relevant in personalized 
medicine as individuals aim to understand visit summaries from their physician, booklets or pamphlets containing information regarding health or disease, or treatment instructions from healthcare professionals. It is also important for global understanding of disease, health, and the healthcare system (Baker et al. 2006).

Health literacy is an important attribute necessary for successful interpretation of healthcare information in many contexts. Research has consistently shown links between higher levels of health literacy and better health outcomes, while inadequate health literacy is associated with poorer health outcomes or reduced health status (Hawkins et al. 2011; Liu et al. 2014). Health literacy is also linked to other socio-demographic factors associated with health disparities. For example, inadequate health literacy in an outpatient heart failure sample was associated with demographic characteristics including lower levels of education, higher age, and lower SES (Peterson et al. 2011). Research has shown inadequate health literacy to be highly prevalent in populations that are older, have lower education attainment and lower SES, are nonEnglish speaking, and are from immigrant backgrounds (Beauchamp et al. 2015; Sentell et al. 2014). Furthermore, individuals from these groups may experience difficulty understanding medical information, causing them to lack confidence in the healthcare system (Beauchamp, et al. 2015). However, health literacy is also a correlate of health outcomes independent of other socio-demographic characteristics. For example, inadequate health literacy has been shown to be independently associated with all-cause mortality (Peterson et al. 2011).

Inadequate health literacy is an example of a socio-demographic variable with an effect on poorer health outcomes that is mediated by beliefs and health behavior participation in the proposed process model. However, it is necessary to identify the beliefs and social cognition constructs that mediate the effects of inadequate health literacy on health behaviors and 
outcomes (Hagger et al. 2018). This may pave the way for interventions aimed at promoting better health outcomes targeting beliefs that are antecedent to health behaviors rather than health literacy which may be more difficult to modify. Interventions that target these mediating social cognition constructs and beliefs may be effective in minimizing health disparities in populations with inadequate health literacy.

For example, risk (Janz and Becker 1984) and illness (Hagger et al. 2017; Leventhal et al. 2016) perceptions are candidate social cognition constructs that may mediate the relationship between inadequate health literacy and health outcomes consistent with the process model. In an illustrative example, Adams et al. (2013) examined health literacy and perceptions of health risk behaviors associated with cancer in a large sample of Australian adults. They found that inadequate health literacy was associated with inaccurate risk perceptions for cancer. Specifically, participants who did not think that smoking, alcohol consumption, or poor diet were risk factors for cancer were more likely to have inadequate health literacy than participants who viewed them as risk factors. In addition, beliefs about cancer were also found to be associated with lifestyle behaviors (cigarette smoking, eating fruit and vegetables, and physical activity). Although the authors presented a model which illustrated an indirect effect of health literacy on lifestyle behaviors mediated by perceptions of cancer, Adams et al. (2013) did not formally test the effect. These implied links are illustrated in the specific version of the process model in Figure 3b. It is also important to note that the beliefs identified in the Adams et al. (2013) study focus on the illness or condition rather than performance of the health behavior, a distinction that has been identified elsewhere (e.g., Hagger et al. 2016 2019), and the extent to whether illness beliefs or beliefs about behaviors serve as mediators is an empirical question in need of further research. Nevertheless, targeting change in the beliefs associated with inadequate health literacy 
in this setting can be paramount in promoting increased participation in health promoting behaviors which may, ultimately, lead to better health outcomes and minimize observed disparities due to differences in health literacy.

In summary, inadequate health literacy levels have been shown to be related to health disparities in multiple populations and for various health outcomes. Research has suggested that beliefs may potentially act as mediators between health literacy and health behaviors and outcomes (Adams et al. 2013). These mediators can be targeted in behavioral interventions to change the beliefs associated with adaptive health behaviors and outcomes, and, in so doing, may minimize health disparities indicated by inadequate health literacy.

\section{Religiosity}

The previous section discussed how socio-demographic variables like ethnicity, SES, and health literacy are related to certain psychological beliefs and social cognition constructs that are related to behaviors and health outcomes. Another socio-structural factor that has been shown to be related to health disparities and also to individuals' health behaviors and outcomes is religiosity (Koenig et al. 2001). Although a link between religiosity and health may not seem immediately intuitive, there is evidence to suggest that it is linked to health outcomes, and can play an important role in determining whether people will engage in health promoting behaviors (Shelton et al. 2013; Benjamins and Brown 2004; Benjamins et al. 2006).

Religiosity is associated with many health behaviors, such as physical activity engagement, diet, sexual behavior, cholesterol, smoking, general safety, and sleep (Koenig et al. 2012). Many religious beliefs have a specific doctrine related to health behaviors, such as diet, sexual activity, and substance use. Some religious doctrines directly promote engagement in adaptive health behaviors, whereas others may indirectly promote engagement in adaptive health 
behaviors. For example, Seventh Day Adventists' doctrine emphasizes the importance of eating a healthy diet, engaging in physical activity, and abstaining from alcohol, tobacco, and caffeinated beverages. Such health behaviors have been identified as the links between religious engagement and mortality among practitioners (Morton et al. 2017). More indirectly, many religions hold the belief that the human body must be cared for because it is a 'sacred creation', referred to as body sanctification beliefs (Mahoney, Pargament et al. 2005; Park 2007). Body sanctification beliefs have been significantly associated with engagement in adaptive health behaviors, and better health outcomes (Mahoney, Carels et al. 2005). However, some view such care as an expression of vanity, which is deemed sinful in some faiths (Griffith 2004). In these instances, personal motives for engagement in health behaviors may differentiate whether taking care of one's body is righteous (obedient to God) or unrighteous (for attention, or vanity; Anderson 2011).

Moreover, some religions promote the belief that God controls life events and members of these groups may engage in less health promoting behaviors because they do not feel as if they are in control of their health outcomes (Rose et al. 2000; Blocker et al. 2006).

Health locus of control (Wallston et al. 1976), the extent to which individuals believe they are in control of their health, is a candidate mediator of the effect of religious beliefs on health outcomes. Religious beliefs may be positively or negatively associated with health-related locus of control depending on the specific nature of those beliefs. For example, believing that one's body is a gift from their god may motivate people to be more proactive when it comes to maintaining their own health because it is seen as a sacred duty (Mahoney, Pargament et al. 2005). Individuals holding these beliefs may be more likely to participate in health promoting behaviors, such as cancer screening or treatment adherence, associated with adaptive health outcomes like better health and symptom relief. In contrast, beliefs in an omnipotent god who 
actively controls life events and outcomes may undermine individuals' sense of personal control and, specifically, health locus of control. For example, low perceived control over health could undermine attitudes and outcome expectancies with respect to health promoting behaviors, which can lead to maladaptive health outcomes like disease progression and worsening of symptoms (Rose et al. 2000; Blocker et al. 2006). This is illustrated in the specific form of the process model in Figure 4. Religiosity may serve as potential correlate of treatment beliefs that subsequently impact engagement in either health promoting or health compromising behaviors, which ultimately contribute to the health outcomes experienced by individuals belonging to various religious groups. Identifying these beliefs and determining how they can be affected by interventions is important for researchers and practitioners interested in improving health outcomes and reducing the health disparities that are associated with certain religious beliefs.

Interestingly, research has suggested that religious beliefs that enhance internal perceptions of control in which people perceive their god provides them with support to meet their health goals. This sense of support has been referred to as god-mediated control (Berrenberg 1987; Krause 2005). God-mediated control may be especially prevalent among older adults, for whom it may serve to compensate for age-related declines in internal control (Hayward and Krause 2013), suggesting that a certain degree of external control related to religious belief may serve to enhance perceptions of internal control (Welton et al. 1996) and health outcomes.

In contrast, religious beliefs may influence individuals to have externalized perceptions of control over their health. Faiths which strongly emphasize or value belief in miraculous healing may be less motivated to engage in health promoting behaviors because they anticipate that their problems will be resolved through 'divine intervention'. These beliefs may therefore be 
linked to low outcome expectancies and attitudes toward health behaviors and low perceived locus of control. Such beliefs may not completely undermine perceived internal control because miracles are likely seen as rare occurrences. However, religious beliefs emphasizing godmediated control may contribute to a sense of religious fatalism, or a relative powerlessness of personal agency and medical intervention, increasing a sense that one's life is ultimately determined by external forces.

Religious fatalism has been linked to maladaptive health outcomes (Franklin et al. 2007; 2008). Researchers have demonstrated that specific forms of health locus of control are associated with health outcomes such as the God Locus of Health Control (Wallston et al. 1999), which reflects beliefs that health is determined by God's will, and the Spiritual Health Locus of Control (Debnam et al. 2012; Holt et al. 2003), which differentiates between active and passive elements of religious and spiritual beliefs. God Locus of Health Control has been found to be related to maladaptive health outcomes (Franklin et al. 2007; 2008). While active elements of Spiritual Health Locus of Control (e.g. engaging in behaviors to maintain one's health) support empowerment to manage health problems, while passive elements (e.g. allowing God to maintain one's health) are related to reduced participation in health behaviors (Holt et al. 2003; Debnam et al. 2012).

In summary, knowledge of the religious beliefs of a population and how they relate to health beliefs, participation in health behaviors, and health outcomes is important for the development of behavioral interventions that encourage participation in health promoting behaviors. In particular, knowledge of how religiosity is linked to the beliefs that serve as antecedents of health behaviors may signal targets for intervention, particularly if religious 
beliefs are associated with low levels of participation in health behaviors and disparities in health.

\section{F. Conclusion}

Research on health disparities has generally focused on establishing relations between socio-demographics and structural variables and poorer health. Fewer studies have examined the mechanisms underpinning these relations and their implications for behavioral interventions. The current chapter has presented a process model that outlines how beliefs and constructs from social cognition theories about health behaviors serve to mediate relations between sociostructural constructs that are linked to health disparities, and how they relate to health behaviors and health outcomes. The current model is important because many social-structural variables are fixed or relatively unchangeable, and are, therefore, not feasible targets for change through intervention. Rather, health behaviors and outcomes are more conducive to change through targeting the antecedent beliefs and social cognition constructs that mediate the relations between social-structural constructs and health outcomes. In this chapter, multiple examples have been presented illustrating the applicability of the proposed model as a means to indicate how characteristics linked to disadvantage relate to health behavior participation and health outcomes via potentially modifiable mediating beliefs and cognitions. The versatility of the model has been demonstrated across a variety of different domains and in different populations and health conditions. However, many of the specified links outlined in the present chapter are speculative, and not based on direct tests of the indirect effects implied in the process model. This is because research applying this model is relatively sparse, and there is an urgent need for more research to verify its predictions more broadly. 
Future researchers should identify additional social cognition constructs and beliefs that serve as mediators of the link between socio-structural variables that represent disadvantaged groups and health behaviors and outcomes. In addition, researchers should also seek to further explore potential moderators of relations between the socio-structural variables related to health disparities, psychological mediators, and health behaviors and outcomes identified in the basic process model. It would also be important to examine how the socio-structural variables linked psychological constructs interact in determining health behaviors and outcomes within the model (cf., Schüz et al. 2017; 2020). It may also be that some socio-structural variables moderate the indirect effect of the effects of other socio-structural variables on health behaviors and outcomes mediated by psychological constructs, a mediated moderation pattern of effects (e.g., Godin et al. 2010; Hamilton and Hagger 2018). As a consequence, some socio-structural variables may serve dual mediating and moderating functions in the model.

Furthermore, future researchers should identify the techniques and methods that affect change in social cognition constructs and beliefs that have been reliably found to mediate the effects of socio-structural variables on health behaviors and outcomes in populations with health disparities. The current process model may, therefore, serve to inform the design of successful behavioral interventions to reduce health disparities. It is important to note that the constructs and beliefs vary across groups and individuals (Johnson et al. 2008), and because such differences exist, interventions must be tailored to target beliefs specific to the population of interest. Thus, the process model discussed throughout this chapter may be used to inform the development of intervention studies designed to target and change the specific psychological processes of individuals belonging to various groups affected by health disparities in order to change their resulting behaviors and improve health outcomes (Hagger, Moyers et al. 2020; 
Rothman et al. 2020). Formative research on the mediating constructs and beliefs will, therefore, be essential to inform the development of future interventions. Ultimately, such interventions should pave the way for the model to be tested experimentally by affecting change among targeted constructs and determining whether they account for change in health behaviors and outcomes, independent of the socio-structural factors that represent disparities. Developing an evidence base of target constructs and interventions that change those constructs may contribute to reducing health inequality and lower the prevalence of illness and disease among individuals belonging to disadvantaged groups. Such efforts will make an essential contribution toward the enhancement of long-term global health and illness prevention. 


\section{G. References}

Adams, RJ, Piantadosi, C, Ettridge, K, Miller, C, Wilson, C, Tucker, G, Hill, CL (2013) Functional health literacy mediates the relationship between socio-economic status, perceptions and lifestyle behaviors related to cancer risk in an Australian population. Patient Education and Counseling 91(2):206-212 https://doi.org/10.1016/j.pec.2012.12.001

Ajzen, I, Fishbein, M (1980) Understanding attitudes and predicting social behavior. New Jersey, Prentice Hall

Ajzen, I (1985) From intentions to actions: A theory of planned behavior. In: Kuhl J Beckmann J (eds), Action-Control: From cognition to behavior. Heidelberg, Germany, Springer, p 11-39

Aklin, WM, Stoeckel, L, Green, P, Keller, C, King, JW, Nielsen, L, Hunter, C (2020) Commentary: National Institutes of Health (NIH) Science of Behavior Change (SOBC) Health Psychology Review https://doi.org/10.1080/17437199.2020.1716383

Anderson, J (2011) Vanity vs. Gluttony: Competing Christian discourses on personal health. Journal of Applied Communication Research 39(4):370-388

\section{https://doi.org/10.1080/00909882.2011.608699}

August, KJ, Sorkin, DH (2011) Racial/ethnic disparities in exercise and dietary behaviors of middleaged and older adults. Journal of General Internal Medicine 26(3):245-250 https://doi.org/10.1007/s11606-010-1514-7

Baker, DW (2006) The meaning and the measure of health literacy. Journal of General Internal Medicine 21(8):878-883 https://doi.org/10.1111/j.1525-1497.2006.00540.x

Basu, S, Andrews, J, Kishore, S, Panjabi, R, Stuckler, D (2012) Comparative performance of private and public healthcare systems in low-and middle-income countries: A systematic review. PLoS Medicine 9(6) https://doi.org/10.1371/journal.pmed.1001244 
Beauchamp, A, Buchbinder, R, Dodson, S, Batterham, RW, Elsworth, GR, McPhee, C, Sparkes, L, Hawkins, M, Osborne, RH (2015) Distribution of health literacy strengths and weaknesses across socio-demographic groups: A cross-sectional survey using the Health Literacy Questionnaire (HLQ) BMC Public Health 15(1):678 https://doi.org/10.1186/s12889-015-2056-z

Benjamins, MR, Brown, C (2004) Religion and preventative health care utilization among the elderly. Social Science Medicine 58(1):109-118 https://doi.org/10.1016/s0277-9536(03)00152-7

Benjamins, MR, Trinitapoli, J, Ellison, CG (2006) Religious attendance, health maintenance beliefs, and mammography utilization: Findings from a nationwide survey of Presbyterian women. Journal for the Scientific Study of Religion 45(4):597-607 https://doi.org/10.1111/j.14685906.2006.00330.x

Berrenberg, JL (1987) The Belief in Personal Control Scale: A measure of God-mediated and exaggerated control. Journal of Personality Assessment 51(2):194-206 https://doi.org/10.1207/s15327752jpa5102_4

Blocker, DE, Romocki, LS, Thomas, KB, Jones, BL, Jackson, EJ, Reid, L, Campbell, MK (2006) Knowledge, beliefs and barriers associated with prostate cancer prevention and screening behaviors among African-American men. Journal of the National Medical Association 98(8):1286-1295

Braveman, P (2006) Health disparities and health equity: Concepts and measurement. Annu Rev Public Health 27:167-194 https://doi.org/10.1146/annurev.publhealth.27.021405.102103

Carey, RN, Connell, LE, Johnston, M, Rothman, AJ, de Bruin, M, Kelly, MP, Michie, S (2019) Behavior change techniques and their mechanisms of action: A synthesis of links described in published intervention literature. Annals of Behavioral Medicine 53(8):693-707 https://doi.org/10.31234/osf.io/x5372 
Chen, FM, Fryer, G. E, Phillips, RL, Wilson, E, Pathman, DE (2005) Patients’ beliefs about racism, preferences for physician race, and satisfaction with care. The Annals of Family Medicine 3(2):138-143 https://doi.org/10.1370/afm.282

Chew, LD, Griffin, JM, Partin, MR, Noorbaloochi, S, Grill, JP, Snyder, A, Bradley, KA, Nugent, SM, Baines, AD, VanRyn, M (2008) Validation of screening questions for limited health literacy in a large VA outpatient population. Journal of General Internal Medicine 23(5):561-566 https://doi.org/10.1007/s11606-008-0520-5

Chu, S. Y, Barker, LE, Smith, PJ (2004) Racial/ethnic disparities in preschool immunizations: United States, 1996-2001. American Journal of Public Health 94(6):973-977 https://doi.org/10.2105/AJPH.94.6.973

Connell, LE, Carey, RN, de Bruin, M, Rothman, AJ, Johnston, M, Kelly, MP, Michie, S (2019) Links between behavior change techniques and mechanisms of action: An expert consensus study. Annals of Behavioral Medicine 53(8):708-720 https://doi.org/10.1093/abm/kay082

Crook, E. D, Peters, M (2008) Health disparities in chronic diseases: Where the money is. The American Journal of the Medical Sciences 335(4):266-270 https://doi.org/10.1097/MAJ.0b013e31816902f1

Debnam, KJ, Holt, CL, Clark, EM, Roth, DL, Foushee, HR, Crowther, M, Fouad, M, Southward, PL (2012) Spiritual health locus of control and health behaviors in African Americans. American Journal of Health Behavior 36(3):360-372 https://doi.org/10.5993/ajhb.36.3.7

Decker, KM, Demers, AA, Nugent, Z, Biswanger, N, Singh, H (2015) Longitudinal rates of colon cancer screening use in Winnipeg, Canada: The experience of a universal health-care system with an organized colon screening program. The American Journal of Gastroenterology 110(12):1640 -1646 https://doi.org/10.1038/ajg.2015.206 
Dehlendorf, C, Bryant, AS, Huddleston, HG, Jacoby, VL, Fujimoto, VY (2010) Health disparities: Definitions and measurements. American Journal of Obstetrics Gynecology 202(3):212-213 https://doi.org/10.1016/j.ajog.2009.12.003

DeWalt, DA, Berkman, ND, Sheridan, S, Lohr, KN, Pignone, MP (2004) Literacy and health outcomes. Journal of General Internal Medicine 19(12):1228-1239 https://doi.org/10.1111/j.15251497.2004.40153.x

Doubeni, CA, Laiyemo, AO, Major, JM, Schootman, M, Lian, M, Park, Y, Graubard, BI, Hollenbeck, AR, Sinha, R (2012) Socioeconomic status and the risk of colorectal cancer: An analysis of more than a half million adults in the National Institutes of Health-AARP Diet and Health Study. Cancer 118(14):3636-3644 https://doi.org/10.1002/cncr.26677

Everson, SA, Maty, SC, Lynch, JW, Kaplan, GA (2002) Epidemiologic evidence for the relation between socioeconomic status and depression, obesity, and diabetes. Journal of Psychosomatic Research 53(4):891-895 https://doi.org/10.1016/s0022-3999(02)00303-3

Fishbein, M, Triandis, HC, Kanfer, FH, Becker, M, Middlestadt, SE, Eichler, A (2001) Factors influencing behavior and behavior change. In Baum A, Revenson TA, Singer JE (eds), Handbook of Health Psychology. Mahwah, NJ, Lawrence Erlbaum, p 3-17

Franklin, MD, Schlundt, DG, McClellan, LH, Kinebrew, T, Sheats, J, Belue, R, Brown, R, Smikes, A, Patel, D, Hargreaves, M (2007) Religious fatalism and its association with health behaviors and outcomes. American Journal of Health Behavior 31(6):563-572 https://doi.org/10.5993/ajhb.31.6.1

Franklin, MD, Schlundt, DG, Wallston, KA (2008) Development and validation of a religious health fatalism measure for the African-American faith community. Journal of Health Psychology 13(3):323-335 https://doi.org/10.1177/1359105307088137 
Freedman, VA, Grafova, IB, Rogowski, J (2011) Neighborhoods and chronic disease onset in later life. American Journal of Public Health 101(1):79-86 https://doi.org/10.2105/AJPH.2009.178640

Glover, JD, Tennant, SK, Hetzel, DM (2004) The socioeconomic gradient and chronic illness and associated risk factors in Australia. Australia and New Zealand Health Policy 1(1):1-8 https://doi.org/10.1071/HP040108

Godin, G, Sheeran, P, Conner, M, Belanger-Gravel, A, Cecilia, M, Gallani, BJ, Nolin, B (2010) Social structure, social cognition, and physical activity: A test of four models. British Journal of Health Psychology 15(1):79-95 https://doi.org/10.1348/135910709x429901

Griffith, RM (2004) Born again bodies: Flesh and spirit in American Christianity (Vol. 12) Berkeley, University of California Press

Hagger, MS, Cameron, LD, Hamilton, K, Hankonen, N, Lintunen, T (2020) Changing behavior: A theory- and evidence-based approach. In Hagger MS, Cameron LD, Hamilton K, Hankonen N, Lintunen T (eds) The Handbook of Behavior Change, Cambridge University Press

Hagger, MS, Hamilton, K (2020) Changing behavior using integrated theories In Hagger MS, Cameron LD, Hamilton K, Hankonen N, Lintunen T (eds) The Handbook of Behavior Change, Cambridge University Press

Hagger, MS, Hamilton, K, Hardcastle, SJ, Hu, M, Kwok, S, Lin, J, Nawawi, HM, Pang, J, Santos, RD, Soran, H, Su, T-C, Tomlinson, B, Watts, GF (2019) Predicting intention to participate in selfmanagement behaviors in patients with familial hypercholesterolemia: A cross-national study. Social Science Medicine 242:112591 https://doi.org/10.1016/j.socscimed.2019.112591

Hagger, MS, Hardcastle, SJ, Hingley, C, Strickland, E, Pang, J, Watts, GF (2016) Predicting selfmanagement behaviors in familial hypercholesterolemia using an integrated theoretical model: 
The impact of beliefs about illnesses and beliefs about behaviors. International Journal of Behavioral Medicine 23(3):282-294 https://doi.org/10.1007/s12529-015-9531-x

Hagger, MS, Hardcastle, SJ, Hu, M, Kwok, S, Lin, J, Nawawi, HM, Pang, J, Santos, RD, Soran, H, Su, T, Watts, GF (2018) Health literacy in familial hypercholesterolemia: A cross-national study. European Journal of Preventive Cardiology 25(9):936-943 https://doi.org/10.1177/2047487318766954

Hagger, MS, Koch, S, Chatzisarantis, NLD, Orbell, S (2017) The common-sense model of selfregulation: Meta-analysis and test of a process model. Psychological Bulletin 143(11):1117-1154 https://doi.org/10.1037/bul0000118

Hagger, MS, Moyers, S, McAnally, K, McKinley, LE (2020) Known knowns and known unknowns on behavior change interventions and mechanisms of action. Health Psychology Review https://doi.org/10.1080/17437199.2020.1719184

Hales, CM, Fryar, CD, Carroll, MD, Freedman, DS, Ogden, CL (2018) Trends in obesity and severe obesity prevalence in US youth and adults by sex and age, 2007-2008 to 2015-2016. JAMA 319(16):1723-1725 https://doi.org/10.1001/jama.2018.3060

Hamilton, K, Hagger, MS (2018) Effects of self-efficacy on healthy eating depends on normative support: A prospective study of long-haul truck drivers. International Journal of Behavioral Medicine 25(2):265-270 https://doi.org/10.1007/s12529-017-9685-9

Harrell, JS, Bangdiwala, SI, Deng, S, Webb, JP, Bradley, C (1998) Smoking initiation in youth: The roles of gender, race, socioeconomics, and developmental status. Journal of Adolescent Health 23(5):271-279 https://doi.org/10.1016/s1054-139x(98)00078-0

Hartley, D (2004) Rural health disparities, population health, and rural culture. American Journal of Public Health 94(10):1675-1678 https://doi.org/10.2105/ajph.94.10.1675 
Hawkins, K, Ozminkowski, RJ, Bottone, FG, Ekness, JG, Hommer, C, Migliori, RJ, Yeh, CS (2011) Relationship between Health Literacy and Health Status Among Participants in a Congestive Heart Failure Disease Management Program, Journals Department, Evans rd, Cary, NC 27513 USA, Oxford University Press, p 438-438

Hayes, AF (2018) Introduction to mediation, moderation, and conditional process analysis: A regression-based approach (2nd ed.) New York, NY, Guildford Press

Hayward, RD, Krause, N (2013) Trajectories of late-life change in God-mediated control. Journals of Gerontology Series B: Psychological Sciences and Social Sciences 68(1):49-58 https://doi.org/10.1093/geronb/gbs054

Hewitson, P, Glasziou, P, Watson, E, Towler, B, Irwig, L (2008) Cochrane systematic review of colorectal cancer screening using the fecal occult blood test (hemoccult): An update. American Journal of Gastroenterology 103(6):1541-1549 https://doi.org/10.1111/j.15720241.2008.01875.x

Hewitson, P, Glasziou, P, Irwig, L, Towler, B, Watson, E (2007) Screening for colorectal cancer using the faecal occult blood test, Hemoccult. The Cochrane database of systematic reviews 2007(1): CD001216 https://doi.org/10.1002/14651858.cd001216.pub2

Holt, CL, Clark, E. M, Kreuter, MW, Rubio, DM (2003) Spiritual health locus of control and breast cancer beliefs among urban African American women. Health Psychology 22(3):294 https://doi.org/10.1037/0278-6133.22.3.294

Hyde, TB, Dentz, H, Wang, SA, Burchett, HE, Mounier-Jack, S, Mantel, CF, Group, N. V. I. I. P. L. W (2012) The impact of new vaccine introduction on immunization and health systems: A review of the published literature. Vaccine 30(45):6347-6358 https://doi.org/10.1016/j.vaccine.2012.08.029 
International Agency for Research on Cancer (2018) Estimated cancer incidence, mortality and prevalence worldwide in 2012. Globocan:2018. http://globocan.iarc.fr/Pages/fact_sheets_cancer.aspx Accessed 12 January 2019

Janz, NK, Becker, MH (1984) The health belief model: A decade later. Health Education Quarterly 11(1):1-47 https://doi.org/10.1177/109019818401100101

Jiang, Y, Hesser, JE (2006) Associations between health-related quality of life and demographics and health risks. Results from Rhode Island's 2002 behavioral risk factor survey. Health and Quality of Life Outcomes 4(1):14 https://doi.org/10.1186/1477-7525-4-14

Johnson, CE, Mues, KE, Mayne, SL, Kiblawi, AN (2008) Cervical cancer screening among immigrants and ethnic minorities: A systematic review using the Health Belief Model. Journal of Lower Genital Tract Disease 12(3):232-241 https://doi.org/10.1097/lgt.0b013e31815d8d88

Joseph, DA, King, JB, Miller, JW, Richardson, LC (2012) Prevalence of colorectal cancer screening among adults--Behavioral Risk Factor Surveillance System, United States, 2010. MMWR $61(2): 51-56$

Koenig, HG, King, D, Carson, VB (2012) Handbook of religion and health. Oxford University Press

Koenig, HG, McCullough, ME, Larson, DB (2001) Religion and health. New York, NY, Oxford University Press

Kopelman, P (2007) Health risks associated with overweight and obesity. Obesity Reviews 8(1):13-17 https://doi.org/10.1111/j.1467-789X.2007.00311.X

Krause, N (2005) God-mediated control and psychological well-being in late life. Research on Aging 27(2):136-164 https://doi.org/10.1177/0164027504270475

LaVeist, TA, Bowie, JV, Cooley-Quille, M (2000) Minority health status in adulthood: The middle years. Health Care Financing Review 21(4):1-13. 
Lee, RL, Loke, AJY (2005) Health-promoting behaviors and psychosocial well-being of university students in Hong Kong. Public Health Nursing 22(3):209-220 https://doi.org/10.1111/j.07371209.2005.220304.x

Leventhal, H, Phillips, LA, Burns, E (2016) The common-sense model of self-regulation (CSM): A dynamic framework for understanding illness self-management. Journal of Behavioral Medicine 39(6):935-946 https://doi.org/10.1007/s10865-016-9782-2

Li, ASW, Figg, G, Schüz, B (2019) Socioeconomic status and the prediction of health promoting dietary behaviours: A systematic review and meta-analysis based on the theory of planned behaviour. Applied Psychology: Health and Well-Being 11(3):382-406 https://doi.org/10.1111/aphw.12154

Lippke, S, Nigg, CR, Maddock, JE (2012) Health-promoting and health-risk behaviors: Theory-driven analyses of multiple health behavior change in three international samples. International Journal of Behavioral Medicine 19(1):1-13 https://doi.org/10.1007/s12529-010-9135-4

Liu, K, Cedres, LB, Stamler, J, Dyer, A, Stamler, R, Nanas, S, Berkson, DM, Paul, O, Lepper, M, Lindberg, HA, Marquardt, J, Stevens, E, Schoenberger, JA, Shekelle, RB, Collette, P, Shekelle, S, Garside, D (1982) Relationship of education to major risk factors and death from coronary heart disease, cardiovascular diseases and all causes, Findings of three Chicago epidemiologic studies. Circulation 66(6):1308-1314 https://doi.org/10.1161/01.CIR.66.6.1308

Liu, YB, Liu, L, Li, YF, Chen, YL (2015) Relationship between health literacy, health-related behaviors and health status: A survey of elderly Chinese. International Journal of Environmental Research and Public Health 12(8):9714-9725 https://doi.org/10.3390/ijerph120809714

Mahoney, A, Carels, RA, Pargament, KI, Wachholtz, A, Edwards Leeper, L, Kaplar, M, Frutchey, R (2005) The sanctification of the body and behavioral health patterns of college students. The 
International Journal for the Psychology of Religion 15(3):221-238 https://doi.org/10.1207/s15327582ijpr1503_3

Mahoney, A, Pargament, KI, Cole, B, Jewell, T, Magyar, GM, Tarakeshwar, N, Murray-Swank, NA, Phillips, R (2005) A higher purpose: The sanctification of strivings in a community sample. The International Journal for the Psychology of Religion 15(3):239-262 https://doi.org/10.1207/s15327582ijpr1503_4

McMillan, B, Conner, M (2007) Health cognition assessment. In Ayers ABS, McManus C, Newman S, Wallston K, Weinman J, West R (ed.) Cambridge Handbook of Psychology, Health and Medicine (2nd ed) Cambridge University Press, p 260-266 https://doi.org/10.1017/cbo9780511543579.001

Mesas, AE, Guallar-Castillón, P, León-Munoz, LM, Graciani, A, Lopez-Garcia, E, Gutiérrez-Fisac, JL, Banegas, JR, Rodriguez-Artalejo, F (2012) Obesity-related eating behaviors are associated with low physical activity and poor diet quality in Spain. The Journal of Nutrition 142(7):1321-1328 https://doi.org/10.3945/jn.112.158154

Miller, WR, Thoresen, CE (2003) Spirituality, religion, and health: An emerging research field. American Psychologist 58(1):24-35 https://doi.org/10.1037/0003-066X.58.1.24

Mojtabai, R, Olfson, M (2003) Medication costs, adherence, and health outcomes among Medicare beneficiaries. Health Affairs 22(4):220-229 https://doi.org/10.1377/hlthaff.22.4.220

Morton, KR, Lee, JW, Martin, LR (2017) Pathways from religion to health: Mediation by psychosocial and lifestyle mechanisms. Psychology of Religion and Spirituality 9(1):106 https://doi.org/10.1037/rel0000091 
Murimi, MW, Harpel, T (2010) Practicing preventive health: The underlying culture among low-income rural populations. The Journal of Rural Health 26(3):273-282 https://doi.org/10.1111/j.1748$\underline{0361.2010 .00289 . x}$

Myers, HF, Lewis, TT, Parker-Dominguez, T (2003) Stress, coping and minority health. In Bernal G, Trimble J, Burlew K, Leong F (eds) Handbook of racial and ethnic minority psychology, Thousand Oaks, CA, Sage Publications, p 377-400 https://doi.org/10.4135/9781412976008.n19

Nelson, A (2002) Unequal treatment: Confronting racial and ethnic disparities in health care. Journal of the National Medical Association 94(8):666.

Nielsen, L, Riddle, M, King, JW, Aklin, WM, Chen, W, Clark, D, Collier, S, Czajkowski, S, Esposito, L, Ferrer, R, Green, P, Hunter, C, Khl, K, King, R, Onken, L, Simmons, JM, Stoeckel, L, Stoney, C, Tully, L, Weber, W (2018) The NIH science of behavior change program: Transforming the science through a focus on mechanisms of change. Behaviour Research and Therapy 101:3-11 https://doi.org/10.1016/j.brat.2017.07.002

Onat, A (2001) Risk factors and cardiovascular disease in Turkey. Atherosclerosis 156(1):1-10 https://doi.org/10.1016/S0021-9150(01)00500-7

Orbell, S, Szczepura, A, Weller, D, Gumber, A, Hagger, MS (2017) South Asian ethnicity, socioeconomic status, and psychological mediators of faecal occult blood colorectal screening participation: A prospective test of a process model. Health Psychology 36(12):1161 https://doi.org/10.1037/hea0000525

Ouyang, X, Lou, Q, Gu, L, Mo, Y, Nan, JH, Kong, AP, So, W, Ko, GT, Ma, RC, Chan, JC, Chow, CC (2012) Cardiovascular disease risk factors are highly prevalent in the office-working population of Nanjing in China. International Journal of Cardiology 155(2):212-216 https://doi.org/10.1016/j.ijcard.2010.09.052 
Pampel, FC, Krueger, PM, Denney, JT (2010) Socioeconomic disparities in health behaviors. Annual Review of Sociology 36:349-370 https://doi.org/10.1146/annurev.soc.012809.102529

Park, CL (2007) Religiousness/spirituality and health: A meaning systems perspective. Journal of Behavioral Medicine 30(4):319-328 https://doi.org/10.1007/s10865-007-9111-x

Pascoe, EA, Smart Richman, L (2009) Perceived discrimination and health: A meta-analytic review. Psychological Bulletin 135(4):531 https://doi.org/10.1037/a0016059

Peterson, PN, Shetterly, SM, Clarke, CL, Bekelman, DB, Chan, PS, Allen, LA, Matlock, DD, Majid, DJ, Masoudi, FA (2011) Health literacy and outcomes among patients with heart failure. JAMA 305(16):1695-1701 https://doi.org/10.1001/jama.2011.512

Protogerou, C, Johnson, BT, Hagger, MS (2018) An integrated model of condom use in sub-Saharan African youth: A meta-analysis. Health Psychology 37(6):586-602 https://doi.org/10.1037/hea0000604

Rogers, RW, Prentice-Dunn, S (1997) Protection motivation theory. In Gochman DS (ed), Handbook of health behavior research: Personal and Social Determinants, vol. 1, Plenum Press, p 113-132

Rolnick, SJ, Pawloski, PA, Hedblom, BD, Asche, SE, Bruzek, RJ (2013) Patient characteristics associated with medication adherence. Clinical Medicine Research 11(2):54-65 https://doi.org/10.3121/cmr.2013.1113

Rose, LE, Kim, MT, Dennison, CR, Hill, MN (2000) The contexts of adherence for African Americans with high blood pressure. Journal of Advanced Nursing 32(3):587-594 https://doi.org/10.1046/j.1365-2648.2000.01538.x

Rothman, AJ, Klein, WMP, Sheeran, P (2020) Moving from theoretical principles to intervention strategies: Applying the experimental medicine approach. In Hagger MS, Cameron LD, 
Hamilton K, Hankonen N, Lintunen T (eds) The Handbook of Behavior Change, Cambridge University Press

Sawyer, PJ, Major, B, Casad, BJ, Townsend, SS, Mendes, WB (2012) Discrimination and the stress response: Psychological and physiological consequences of anticipating prejudice in interethnic interactions. American Journal of Public Health 102(5):1020-1026 https://doi.org/10.2105/AJPH.2011.300620

Schüz, B, Brick, C, Wilding, S, Conner, M (2020) Socioeconomic status moderates the effects of health cognitions on health behaviors within participants: Two multibehavior studies. Annals of Behavioral Medicine 54(1):36-48 https://doi.org/10.1093/abm/kaz023

Schüz, B, Li, AS-W, Hardinge, A, McEachan, RR, Conner, M (2017) Socioeconomic status as a moderator between social cognitions and physical activity: Systematic review and meta-analysis based on the Theory of Planned Behavior. Psychology of Sport and Exercise 30:186-195 https://doi.org/10.1016/j.psychsport.2017.03.004

Sentell, T, Zhang, W, Davis, J, Baker, KK, Braun, KL (2014) The influence of community and individual health literacy on self-reported health status. Journal of General Internal Medicine 29(2):298-304 https://doi.org/10.1007/s11606-013-2638-3

Shelton, RC, Snavely, AC, De Jesus, M, Othus, MD, Allen, D (2013) HPV vaccine decision-making and acceptance: Does religion play a role? Journal of Religion and Health 52(4):1120-1130 https://doi.org/10.1007/s10943-011-9553-X

Wallston, BS, Wallston, KA, Kaplan, GD, Maides, SA (1976) Development and validation of the health locus of control (HLC) scale. Journal of Consulting and Clinical Psychology 44(4):580-585 https://doi.org/10.1037/0022-006X.44.4.580 
Wallston, KA, Malcarne, VL, Flores, L, Hansdottir, I, Smith, CA, Stein, MJ, Weisman, MH, Clements, PJ (1999) Does God determine your health? The God locus of health control scale. Cognitive Therapy and Research 23(2):131-142 https://doi.org/10.1023/A:1018723010685

Wardle, J, von Wagner, C, Kralj-Hans, I, Halloran, SP, Smith, SG, McGregor, LM, Vart, G, Howe, R, Snowball, J, Handley, G, Logan, RF, Rainbow, S, Smith, S, Thomas, MC, Counsell, N, Morris, S, Duffy, SW, Hackshaw, A, Moss, S, Atkin, W, Raine, R (2016) Effects of evidence-based strategies to reduce the socioeconomic gradient of uptake in the English NHS Bowel Cancer Screening Programme (ASCEND): Four cluster-randomised controlled trials. The Lancet 387(10020):751-759 https://doi.org/10.1016/s0140-6736(15)01154-X

Watson, JM, Logan, HL, Tomar, SL (2008) The influence of active coping and perceived stress on health disparities in a multi-ethnic low income sample. BMC Public Health 8(1):41 https://doi.org/10.1186/1471-2458-8-41

Waverijn, G, Heijmans, M, Spreeuwenberg, P, Groenewegen, PP (2016) Associations between neighborhood social capital, health literacy, and self-rated health among people with chronic illness. Journal of Health Communication 21(suppl 2):36-44 https://doi.org/10.1080/10810730.2016.1179369

Welton, GL, Adkins, AG, Ingle, SL, Dixon, WA (1996) God control: The fourth dimension. Journal of Psychology and Theology 24(1):13-25 https://doi.org/10.1177/009164719602400102

Williams, DR, Sternthal, MJ (2007) Spirituality, religion and health: Evidence and research directions. The Medical Journal of Australia 186(10):47-50

Winkleby, MA, Fortmann, SP, Barrett, DC (1990) Social class disparities in risk factors for disease: Eight-year prevalence patterns by level of education. Preventive Medicine 19(1):1-12 https://doi.org/10.1016/0091-7435(90)90001-Z 
Figure 1. Basic process model outlining the processes by which socio-demographic and structural variables linked to health disparities relate to health behaviors and outcomes mediated by psychological constructs.

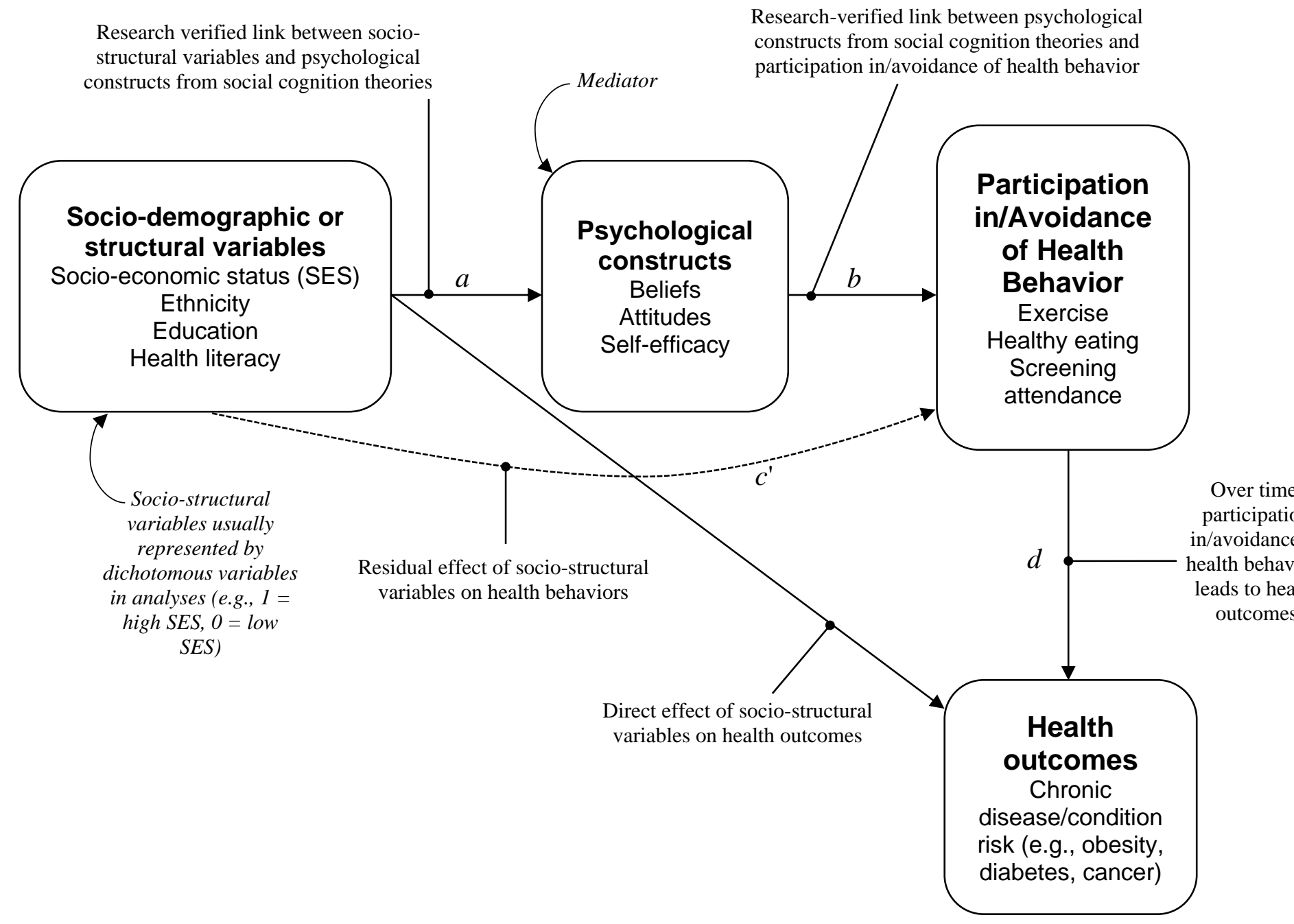


Figure 2. Specific version of the basic process model outlining the process by which socioeconomic status, race, and ethnicity relate to health behaviors (screening uptake in panel a and physician choice in panel b) and health outcomes (cancer risk in panel a and general health outcomes in panel b) mediated by psychological constructs (social cognition and beliefs in panel $a$ and perceived racism/discrimination in panel b).

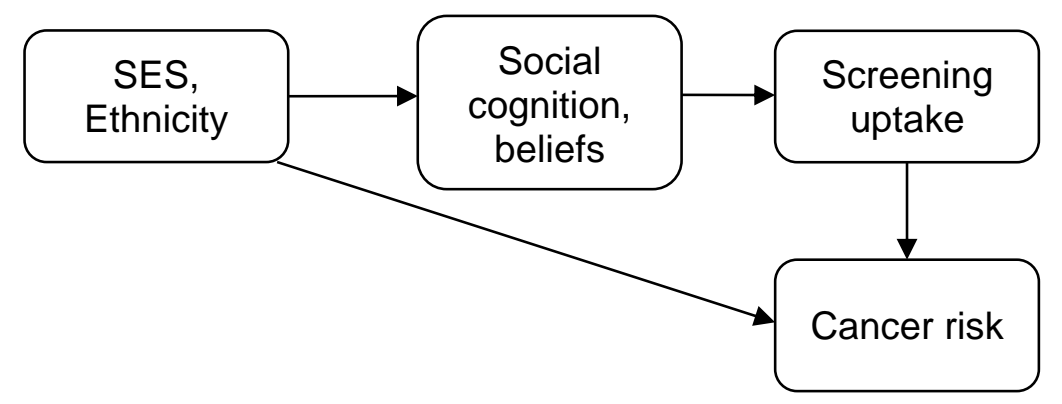

(a)

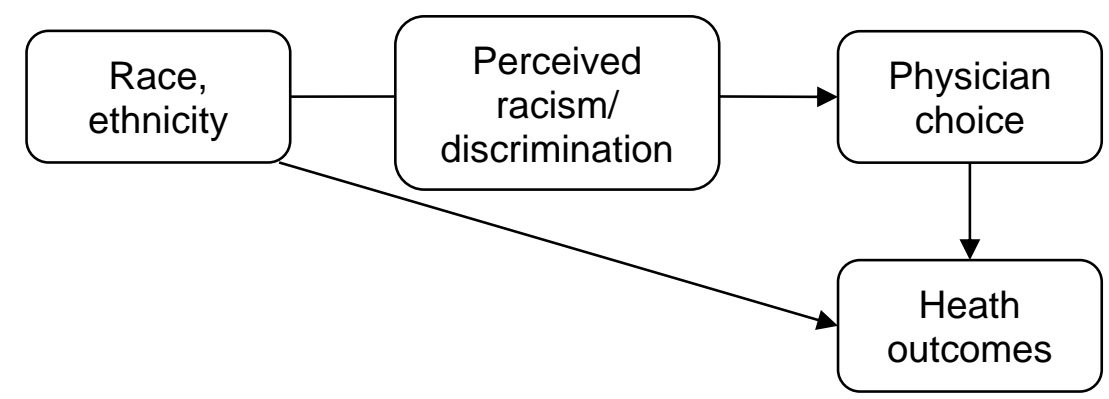

(b) 
Figure 3. Specific version of the basic process model outlining the process by which health literacy relates to health behaviors (mental health treatment in panel a and participation in health behaviors in panel b) and health outcomes (risk of mental health condition in panel a and cancer risk in panel b) mediated by social cognition and beliefs.

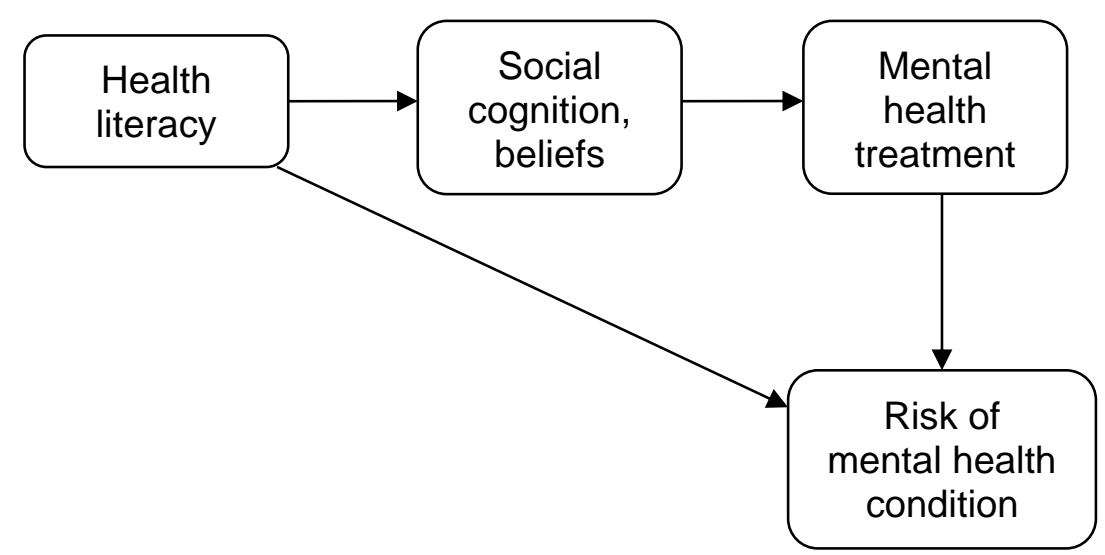

(a)

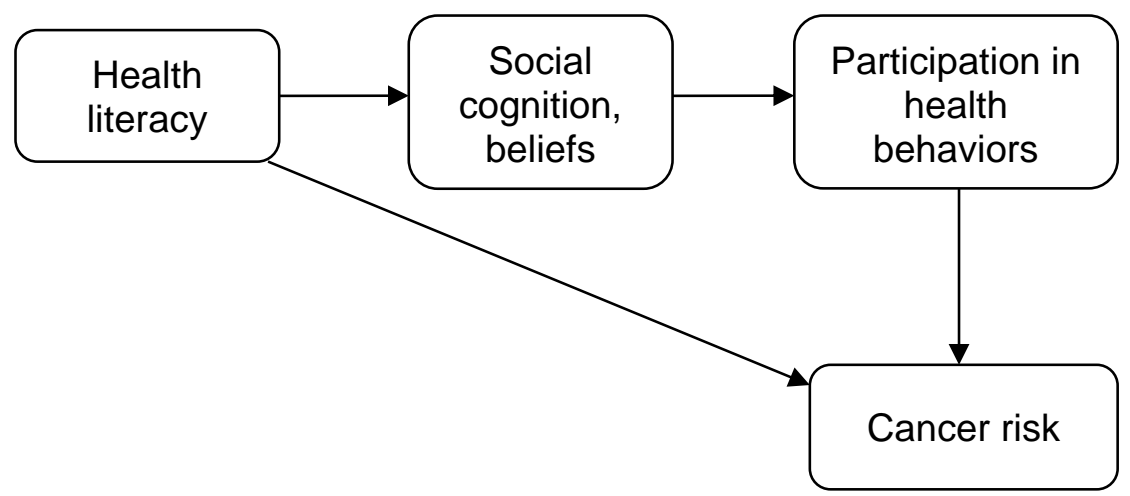

(b) 
Figure 4. Specific version of the basic process model outlining the process by which religiosity relates to health promoting/health compromising behaviors and adaptive/maladaptive health outcomes mediated by beliefs in personal control.

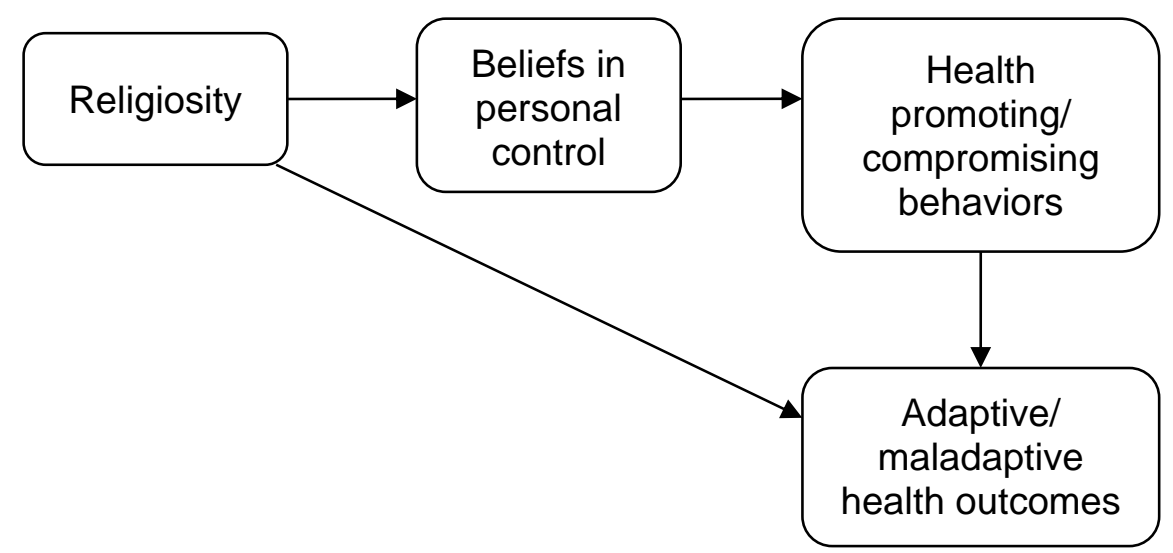

